\title{
Endometrial scratch for infertile polycystic ovary syndrome (PCOS) women undergoing laparoscopic ovarian drilling: a randomized controlled trial
}

\author{
A. Gibreel ${ }^{1 *}\left(\mathbb{D}\right.$, R. Ali ${ }^{3}$, R. Hemida ${ }^{1}$, L. Sherif ${ }^{1}$ and N. El-Adawi ${ }^{2}$
}

\begin{abstract}
Background: Women with polycystic ovarian syndrome (PCOS) may undergo laparoscopic ovarian drilling (LOD). To find out whether endometrial scratch, at time of LOD, could improve live birth rate in subfertile women with PCOS, a randomized controlled trial was conducted.

Results: There was no evidence of a significant difference in cumulative live birth rate between women who had endometrial scratch at time of LOD and those who had LOD only (38.1\% and $34.3 \%$ respectively, odds ratio 1.18 , $95 \% \mathrm{Cl}(0.67,2.07) ; p=0.57)$.

Conclusion: Women undergoing laparoscopic ovarian drilling should not be subjected to endometrial scratch as it does not lead to improvement in live birth rate. The study was prospectively registered on 25 April 2014 in

ClinicalTrials.gov with identifier number NCT02140398.
\end{abstract}

\section{Background}

Polycystic ovarian syndrome is the most common cause of anovulatory subfertility [1]. Weight reduction, lifestyle modification, and ovulation induction are the recommended initial management strategies $[2,3]$. Laparoscopic ovarian drilling (LOD) has been suggested to induce ovulation in these women, especially those who fail to ovulate through ovulatory medications [4-6]. It has been suggested that the procedure is as effective as ovarian stimulation with exogenous gonadotropins [7], yet it does not increase multiple pregnancy rates or ovarian hyperstimulation syndrome (OHSS) rates. Many women may ovulate after LOD, yet they fail to conceive [8]. Those women may need to undergo IVF treatment in their pursuit for a baby.

Endometrial scratching is a procedure where the endometrium is subjected to physical trauma that caused injury to the functional layer of the endometrium

\footnotetext{
* Correspondence: ahmedfathgi@yahoo.com

${ }^{1}$ Obstetrics and Gynecology Department, Mansoura University, Mansoura,

Egypt

Full list of author information is available at the end of the article
}

mechanically [9-12]. It has been suggested that endometrial injury could improve IVF outcome in women with recurrent implantation failure after IVF [13]. Nonetheless, endometrial scratch has been also proposed to overcome subfertility in women with unexplained infertility [14]. Randomized controlled trials have also shown improvements of intrauterine insemination (IUI) results in women subjected to controlled endometrial injury prior to insemination $[9,10]$. However, there were some other studies that have shown no benefit from the procedure $[15,16]$.

The aim of our study was to find out whether performing endometrial scratch at time of laparoscopic drilling would improve live birth rate in subfertile women with PCOS.

\section{Patients and methods}

Study design and participants

We conducted a parallel randomized controlled trial (RCT), approved by our university ethics committee. We approached all infertile women with anovulatory infertility due to PCOS referred for laparoscopic ovarian drilling in Mansoura University Teaching Hospitals in Mansoura, 
Egypt. Our hospital is a tertiary care center conducting between 600 and 700 laparoscopic surgeries per year for infertile women. The study was conducted during the period from April 2014 to April 2015 (last patient enrollment). Follow-up was continued for 9 months after laparoscopy. The last pregnancy was in December 2015. Last data collection was in September 2016. An informed written consent was obtained from all women who participated in the study.

Our inclusion criteria were women aged 20 and less than 39 and women with PCOS as diagnosed by Rotterdam criteria, fertile semen analysis according to WHO 2010, and bilateral tubal patency as demonstrated by hysterosalpingogram (HSG) $[17,18]$. The exclusion criteria were suspected endometriosis, suspected uterine cavity anomaly or mass, associated male factor infertility, presence of endocrinopathy as thyroid dysfunction, and women subjected to endometrial curettage for any reason in the last 6 months.

\section{Intervention}

Women were admitted to our hospital 1 day before laparoscopic drilling. Women were randomized into two groups: group A (the intervention group) and group B (the control group). Randomization was through a computer-generated list of random numbers. Allocation of women to groups was through an opaque sealed envelope that had to be picked by a nurse in the operative theater. The surgeon was not blinded to the procedure while patients and data assessor were blinded to their allocation.

All women underwent a three-puncture laparoscopy procedure where laparoscopic ovarian drilling (LOD) was achieved. Ovarian drilling was performed through monopolar coagulation diathermy. Four punctures were performed. Each penetrates about $4 \mathrm{~mm}$ depth, using $40-\mathrm{W}$ power that lasts for $4 \mathrm{~s}$. In the intervention group (group A), endometrial scratching was performed at the end of laparoscopy by endometrial curette. The curette was introduced gently through the cervix up to the uterine fundus then withdrawn for 1 or $2 \mathrm{~cm}$. One act of scratching was performed on the posterior wall of the uterus after the end of drilling. The obtained specimens were sent for histopathology. The control group (group B) had LOD only, and no endometrial scratch was performed.

Women in both groups were seen 3 months after laparoscopy and were asked whether they had a positive pregnancy test, still have oligomenorrhea, or had had regular periods. Women who had regular periods were subjected to folliculometry to confirm the establishment of ovulation while those with oligomenorrhea were subjected to ovulation induction with clomiphene citrate, tamoxifen, or letrozole. Women who did not respond to ovulatory oral medications were stimulated using exogenous gonadotropins using the low-dose stepup protocol with a 37.5 IU starting dose [19]. The primary outcome measure in this trial was live birth rate per woman randomized. Secondary outcome measures were clinical pregnancy rate, time to pregnancy, miscarriage rate, and multiple pregnancy rate. The study was registered in ClinicalTrials.gov with identifier number NCT02140398.

\section{Definitions}

Clinical pregnancy was defined as the presence of intrauterine gestational sac 1 or 2 weeks after positive pregnancy test in blood. Live birth was defined as the delivery of living fetus after 24 weeks gestation.

\section{Statistical analysis}

We estimated that the pregnancy rate after laparoscopic ovarian drilling was around 50\% [20]. The intervention was suggested to boost pregnancy rate up to $70 \%$. We calculated that we will need to study 93 experimental subjects and 93 control subjects to be able to reject the null hypothesis that the failure rates for experimental and control subjects are equal with a study power (probability) of $80 \%$. The type I error probability associated with this test of this null hypothesis is 0.05 [21]. To compensate for dropouts, we calculated that we needed to randomize 210 women. We used SPSS 15 program. We adopted the intention-to-treat analysis.

\section{Results}

From 250 infertile women with PCOS, who were admitted to Obstetrics and Gynecology Department and were planned for laparoscopy, 220 cases meet eligibility criteria of the study. Two hundred ten infertile women with PCOS agreed to participate (Fig. 1).

There was no difference in women randomized to each group as regards to age, BMI, FSH, and duration of infertility (Table 1).

There were no significant differences in ovulation rate, miscarriage rate, cumulative pregnancy rate, or live birth rate in women in group A compared to women in group B (Table 2).

\section{Discussion}

The results of this randomized trial have shown no benefit of endometrial curettage in women with anovulatory infertility undergoing LOD in terms of pregnancy rate or live birth rate.

Up to our knowledge, there were no published similar trials to compare our results. However, the effect of endometrial scratching in overcoming infertility has been examined in different platforms. Endometrial scratch was suggested to improve pregnancy rates in 


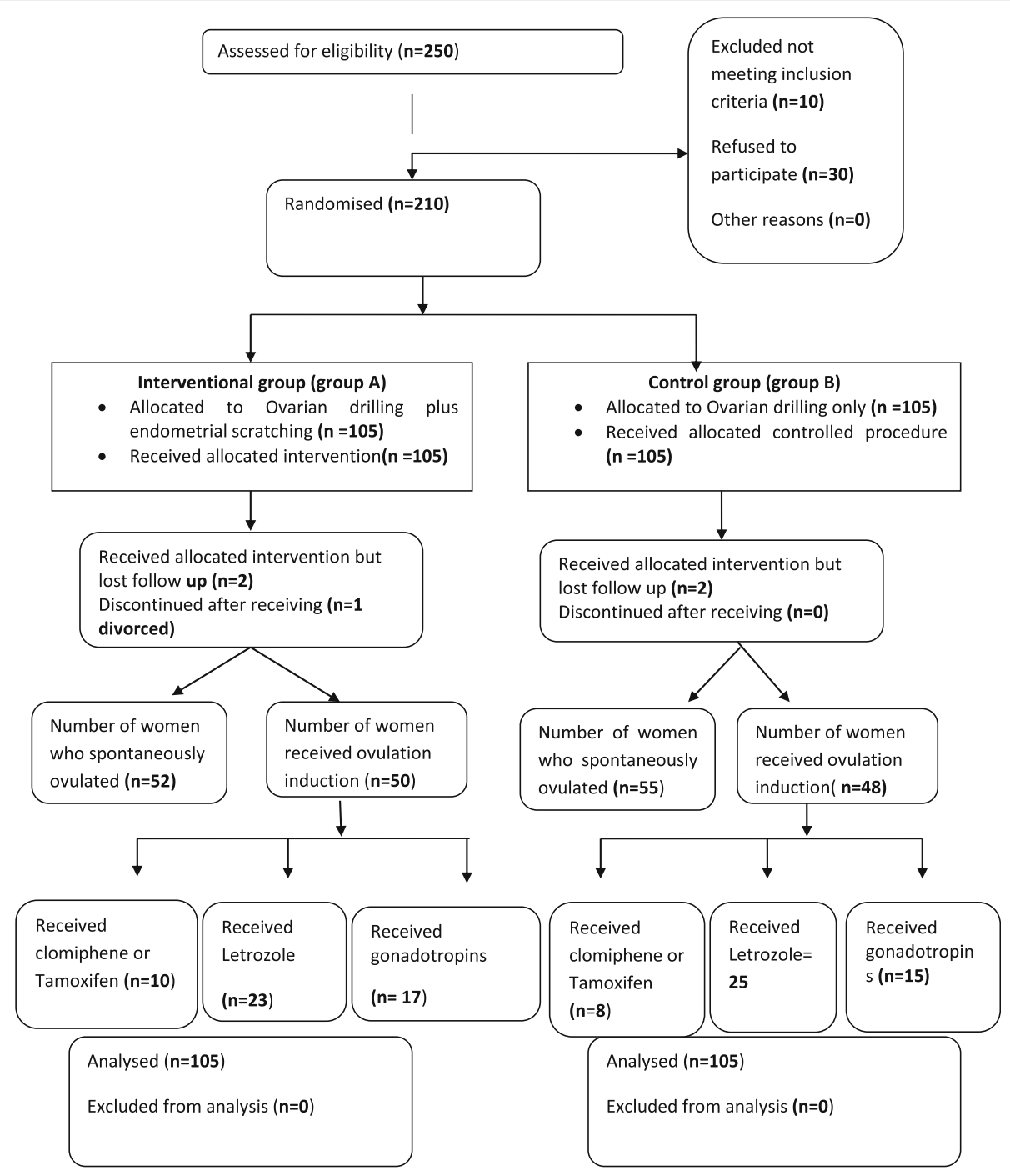

Fig. 1 Flow chart for the study recruitment and analysis process

Table 1 Patients' characteristics

\begin{tabular}{llll}
\hline & $\begin{array}{l}\text { Group (A) } \\
(N=105)\end{array}$ & $\begin{array}{l}\text { Group (B) } \\
(N=105)\end{array}$ & $p$ value \\
\hline Age, mean \pm SD & $26.9 \pm 4.24$ & $26.1 \pm 4.9$ & $p=0.18$ \\
BMI, mean \pm SD & $26.0 \pm 2.7$ & $25.6 \pm 2.76$ & $p=0.35$ \\
$\begin{array}{l}\text { Duration of infertility } \\
\text { (years), mean } \pm \text { SD }\end{array}$ & $4.3 \pm 1.7$ & $4.1 \pm 2.1$ & $p=0.46$ \\
Type of infertility & & & $p=0.23$ \\
$\quad$ 1ry & 79 & 87 & \\
$\quad$ 2ry & 26 & 18 & \\
FSH (IU), mean \pm SD & $5.61 \pm 1.9$ & $5.56 \pm 1.32$ & $p=0.82$ \\
LH (IU), mean $\pm S D$ & $9.49 \pm 2.68$ & $8.89 \pm 3.07$ & $p=0.20$ \\
\hline
\end{tabular}

women undergoing IVF, intrauterine insemination (IUI), or even practicing timed intercourse (TI). Women with unexplained subfertility have shown to have benefitted from the procedure without any further intervention [13]. Endometrial scratching may also boost live birth rate in women undergoing IUI using partners' semen $[9,10]$. Indeed, some published systematic reviews have identified an increase in pregnancy rates in subfertile women undergoing the intervention $[12,22]$.

Many studies had shown a potential benefit of the procedure in improving fertility performance in women with previous IVF failure undergoing a fresh cycle [13, 14]. However, the most recent systematic review has reported no effect of the procedure on women undergoing IVF treatment with a previous one failed IVF cycle [23]. 
Table 2 Clinical outcomes

\begin{tabular}{|c|c|c|c|}
\hline & $\begin{array}{l}\text { Group (A) } \\
(N=105)\end{array}$ & $\begin{array}{l}\text { Group (B) } \\
(N=105)\end{array}$ & $p$ value \\
\hline $\begin{array}{l}\text { Spontaneous ovulation rate, } \\
\text { number (\%) }\end{array}$ & $52(49.5 \%)$ & $55(52.4 \%)$ & $p=0.68$ \\
\hline $\begin{array}{l}\text { Number received ovulation } \\
\text { induction, number (\%) }\end{array}$ & $\begin{array}{l}50 \text { (47.6\%) (two } \\
\text { women lost to } \\
\text { follow-up and } \\
\text { one divorced) }\end{array}$ & $\begin{array}{l}48(45.7 \%) \\
\text { (two women } \\
\text { lost to follow-up) }\end{array}$ & \\
\hline Type of ovulatory medication used & & & $p=0.89$ \\
\hline Clomiphene or tamoxifen & 10 & 8 & \\
\hline Letrozole & 23 & 25 & \\
\hline Gonadotropins & 17 & 15 & \\
\hline $\begin{array}{l}\text { Received nothing or } \\
\text { dropped out }\end{array}$ & 3 & 2 & \\
\hline $\begin{array}{l}\text { Biochemical pregnancy } \\
\text { rate, number (\%) }\end{array}$ & $44(41.9) \%$ & $40(38 \%)$ & $p=0.57$ \\
\hline Live birth rate, number (\%) & 40/105 (38.1\%) & $36 / 105(34.3 \%)$ & $p=0.56$ \\
\hline $\begin{array}{l}\text { Number of pregnancies } \\
\text { (percentage), after LOD } \\
\text { without the use } \\
\text { of ovulatory drugs }\end{array}$ & 29/52 (55\%) & $27 / 55(49 \%)$ & $p=0.56$ \\
\hline $\begin{array}{l}\text { Number of pregnancies } \\
\text { (percentage), after LOD } \\
\text { and ovulatory drugs }\end{array}$ & $11 / 50^{\dagger}(22 \%)$ & $9 / 48^{\ddagger}(18.7 \%)$ & $p=0.71$ \\
\hline Clomiphene or tamoxifen & 3 & 1 & \\
\hline Letrozole & 5 & 6 & \\
\hline Gonadotropins & 3 & 2 & \\
\hline $\begin{array}{l}\text { Interval between laparoscopy and } \\
\text { pregnancy in months, mean } \pm \text { SD }\end{array}$ & $4.4 \pm 1.85$ & $4.36 \pm 1.8$ & $p=0.9$ \\
\hline Miscarriage rate, number (\%) & $4(10 \%)$ & $4(11.1 \%)$ & $p=0.88$ \\
\hline
\end{tabular}

${ }^{\dagger}$ The denominator is women in group A who did not ovulate after LOD after exclusion of dropped out

${ }^{\ddagger}$ The denominator is women in group B who did not ovulate after LOD after exclusion of dropped out

However, there is still uncertainty about the value of the procedure in women undergoing it for the first time [23-25].

Many theories have been proposed to explain the favorable effect of endometrial injury. Endometrial healing, increased implantation mediators, and gene expression theories all had some biological plausibility [26, 27]. In our trial, the population was subfertile PCOS women in whom the apparent factor was anovulation. It seems, based on our findings, that controlled trauma to the endometrium did not make a positive effect to this group of patients.

Our results have shown almost $50 \%$ spontaneous ovulation rate after LOD. This is consistent with the reported $70-80 \%$ ovulation rate in the literature [8]. Women who failed to have spontaneous ovulation following LOD were subjected to ovulation induction [28, 29]. We used clomiphene citrate, tamoxifen, letrozole, and exogenous gonadotropins to induce ovulation in these women. Currently, there is no evidence of a difference in pregnancy rates between clomiphene citrate and tamoxifen in ovulation induction in women with PCOS; hence, we categorized women taking clomiphene and tamoxifen together. This is unlike the current growing evidence that the use of letrozole might be associated with higher pregnancy rates in ovulation induction for women with PCOS [30, 31]

In our study, we observed no evidence of a difference in miscarriage rate between the two groups. The overall miscarriage rate in pregnant women with PCOS varies up to $50 \%$ [8]. A Cochrane systematic review did not find any significant differences in the miscarriage rates in women treated by LOD compared to those adopted other medical modalities [8].

We thought that one of the strength points in our study is that it is a randomized trial with a predetermined sample size calculation. Although we calculated the sample size based on an assumption that pregnancy rates after LOD are $50 \%$, in our series, the overall pregnancy rate was less than this. This might be one of the points that turned out to be the weakness point in this trial. Besides, our follow-up period was extended to only 9 months after drilling. There have been reports 
that the effect of drilling extends up to 1 year. Moreover, many clinicians consider any manipulation in the uterus could provoke an effect similar to the intentional scratching, and in our series, a uterine manipulator was inserted in all cases whether subjected to curettage or not. The implication of our results to the clinical world of subfertility is that we do not recommend doing the procedure for this population at time of laparoscopic drilling. However, it should be clear that our study was examining the effect of endometrial scratch in PCOS women undergoing drilling. We do not know whether the procedure might improve pregnancy rates in PCOS women undergoing ovulation induction through ovulation induction medications alone or not. Extrapolating the evidence from this trial to other interventions done prior to recommending laparoscopic drilling may be inappropriate.

\section{Conclusion}

To conclude, endometrial scratch at time of LOD for subfertile anovulatory women with PCOS may not lead to an improvement of live birth rates.

\section{Abbreviations}

PCOS: Polycystic ovary syndrome; LOD: Laparoscopic ovarian syndrome; IUI: Intrauterine insemination; IVF: In vitro fertilization

\section{Acknowledgements}

The authors would like to express their gratitude to all women who participated in this trial as well as the clinical and nursing staff in the Department of Obstetrics and Gynecology.

\section{Authors' contributions}

AG conceptualized the idea, performed surgeries, and wrote the paper. RA wrote the protocol, obtained the ethical approval and consents, collected the data, and participated in the writing up. This trial was submitted in the thesis submitted by RA for her Master degree. RH conceptualized the idea, performed surgeries, and wrote the paper. LS conceptualized the idea, performed surgeries, and wrote the paper. NE conceptualized the idea and data analysis and participated in writing up the paper. All authors have read and approved the manuscript.

\section{Funding}

The study was funded by Mansoura University. Mansoura University was paying the salaries of all authors. All laparoscopies were performed in Mansoura University Teaching Hospitals which is run and funded by Mansoura University. All costs related to the study were financially covered by either Mansoura University or the researchers themselves. There was no financial contribution from any pharmaceutical company or any other third partner.

\section{Availability of data and materials}

The datasets used and/or analyzed during the current study are available from the corresponding author, upon acceptance by Mansoura University, on reasonable request.

\section{Ethics approval and consent to participate}

The study was ethically approved by Mansoura Faculty of Medicine ethical approval committee. All participants had signed an informed consent, and all consents are saved with patients' data in Mansoura University Teaching Hospital.

\section{Consent for publication}

Not applicable

\section{Competing interests}

The authors declare that they have no competing interests.

\section{Author details}

'Obstetrics and Gynecology Department, Mansoura University, Mansoura, Egypt. ${ }^{2}$ Public Health Department, Mansoura University, Mansoura, Egypt. ${ }^{3}$ Obstetrics and Gynecology, Ministry of Health, Cairo, Egypt.

Received: 3 July 2019 Accepted: 2 August 2019

Published online: 05 September 2019

\section{References}

1. Palomba S, Orio F, Nardo L, Falbo A, Russ CD et al (2004) Metformin administration versus laparoscopic ovarian diathermy in clomiphene citrateresistant women with polycystic ovary syndrome: a prospective parallel randomized double-blind placebo-controlled trial. J Clin Endocrinol Metab 89(10):4801-4809

2. Pauli JM, Raja-Khan N, Wu X, Legro RS (2011) Current perspectives of insulin resistance and polycystic ovary syndrome. Diabet Med 28(12):1445-1454

3. Diamanti-Kandarakis E, Dunaif A (2012) Insulin resistance and the polycystic ovary syndrome revisited: an update on mechanisms and implications. Endocr Rev 33(6):981-1030

4. Kaur M, Pranesh G, Mittal M, Gahlan A, Deepika K, Shashikala T, Rao K (2013) Outcome of laparoscopic ovarian drilling in patients of clomiphene resistant polycystic ovarian syndrome in a tertiary care center. IJIFM 4(2):39-44

5. Kong G, Cheung L, Lok IH (2011) Effects of laparoscopic ovarian drilling in treating infertile anovulatory polycystic ovarian syndrome patients with and without metabolic syndrome. Hong Kong Med J. 17(1):5-10

6. Mitra S, Nayak PK, Agrawal S (2015) Laparoscopic ovarian drilling: an alternative but not the ultimate in the management of polycystic ovary syndrome. J Nat Sci Biol Med 6(1):40

7. Moazami Goudarzi Z, Fallahzadeh H, Aflatoonian A, Mirzaei M (2014) Laparoscopic ovarian electrocautery versus gonadotropin therapy in infertile women with clomiphene citrate-resistant polycystic ovary syndrome: a systematic review and meta-analysis. Iran J Reprod Med 12(8):531-538

8. Farquhar C, Brown J, Marjoribanks J (2012) Laparoscopic drilling by diathermy or laser for ovulation induction in anovulatory polycystic ovary syndrome. Cochrane Database Syst Rev. 6:CD001122

9. $\quad$ Maged A, Al-Inany H, Salama K, Souidan I, Abo Ragab H, Elnassery N (2015) Endometrial scratch injury induces higher pregnancy rate for women with unexplained infertility undergoing IUI with ovarian stimulation: a randomized controlled trial. Reprod Sci 23(2):239-243

10. Mahey R, Goel T, Gupta M, Kachhawa G, Kriplani A (2015) To evaluate the pregnancy rate after endometrial scratching in couples with unexplained infertility in ovulation induction and IUI cycles. Fertil Steril 104(3):e343

11. Lensen S, Sadler L, Farquhar C (2016) Endometrial scratching for subfertility: everyone's doing it. Hum Reprod 31(6):1241-1244

12. Lensen S, Manders M, Nastri C, Gibreel A, Martins W, Templer G, Farquhar C (2016) Endometrial injury for pregnancy following sexual intercourse or intrauterine insemination. Cochrane Database Syst Rev 6:CD011424

13. Karimzadeh M, Ayazi Rozbahani M, Tabibnejad N (2009) Endometrial local injury improves the pregnancy rate among recurrent implantation failure patients undergoing in vitro fertilisation/intra cytoplasmic sperm injection: a randomised clinical trial. Aust N Z J Obstet Gynaecol 49(6):677-680

14. Gibreel A, Badawy A, El-Refai W, El-Adawi N (2013) Endometrial scratching to improve pregnancy rate in couples with unexplained subfertility: a randomized controlled trial. J Obstet Gynaecol Res 39(3):680-684

15. Ashrafi M, Tehraninejad ES, Haghiri M, Masomi M, Sadatmahalleh SJ, Arabipoor A (2017 Sep) The effect of endometrial scratch injury on pregnancy outcome in women with previous intrauterine insemination failure: a randomized clinical trial. J Obstet Gynaecol Res. 43(9):1421-1427. https://doi.org/10.1111/jog.13401

16. Yeung TW, Chai J, Li RH, Lee VC, Ho PC, Ng EH (2014 Nov) The effect of endometrial injury on ongoing pregnancy rate in unselected subfertile women undergoing in vitro fertilization: a randomized controlled trial. Hum Reprod. 29(11):2474-2481

17. World Health Organization (2010) WHO laboratory manual for the examination and processing of human semen, 5th edn. World Health Organization, Geneva

18. Rotterdam ESHRE/ASRM-Sponsored PCOS Consensus Workshop Group (2004) Revised 2003 consensus on diagnostic criteria and long-term health risks related to polycystic ovary syndrome. Fertil Steril 81:19-25 
19. Balasch J1, Fábregues F, Creus M, Casamitjana R, Puerto B, Vanrell JA (2000) Recombinant human follicle-stimulating hormone for ovulation induction in polycystic ovary syndrome: a prospective, randomized trial of two starting doses in a chronic low-dose step-up protocol. J Assist Reprod Genet 17(10): 561-565

20. Fernandez H, Morin-Surruca M, Torre A, Faivre E, Deffieux X, Gervaise A (2011) Ovarian drilling for surgical treatment of polycystic ovarian syndrome: a comprehensive review. Reprod Biomed Online 22:556-568

21. Dupont W, Plummer W (1998) Power and sample size calculations for studies involving linear regression. Control Clin Trials 19:589-601

22. Nastri C, Lensen S, Gibreel A, Raine-Fenning N, Maheshwari A, Ferriani R, Bhattacharya S, Martins W (2015) Endometrial injury in women undergoing assisted reproductive techniques. Cochrane Database of Syst Rev 3: CD009517

23. van Hoogenhuiize NE, Kasius JC, Broekmans FJM, Bosteels J, Torrance HL (2019) Endometrial scratching prior to IVF; does it help and for whom? A systematic review and meta-analysis. Hum Reprod Open. 2019(1):hoy025

24. Gibreel A, El-Adawi N, Elgindy E, Al-Inany H, Allakany N, Tournaye H (2015) Endometrial scratching for women with previous IVF failure undergoing IVF treatment. Gynecol Endocrinol. 31(4):313-316

25. Mahran A, Ibrahim M, Bahaa $\mathrm{H}$ (2016) The effect of endometrial injury on first cycle IVF/ICSI outcome: a randomized controlled trial. Int J Reprod Biomed [Yazd]. 14(3):193-198

26. Li R, Hao G (2009) Local injury to the endometrium: its effect on implantation. Curr Opin Obstet Gynecol 21:236-239

27. Gnainsky Y, Granot I, Aldo P, Barash A, Or Y, Schechtman E, Mor G, Dekel N (2010) Local injury of the endometrium induces an inflammatory response that promotes successful implantation. Fertil Steril 94:2030-2036

28. Bayram N, van Wely M, Kaaijk EM, Bossuyt PM, van der Veen F (2004) Using an electrocautery strategy or recombinant follicle stimulating hormone to induce ovulation in polycystic ovary syndrome: randomised controlled trial. BMJ. 328:192

29. Brown J, Farquhar C (2016) Clomiphene and other antioestrogens for ovulation induction in polycystic ovarian syndrome. Cochrane Database Syst Rev. 12:CD002249

30. Roque M, Tostes AC, Valle M, Sampaio M, Geber S (2015) Letrozole 610 versus clomiphene citrate in polycystic ovary syndrome: systematic review and meta-analysis. Gynecol Endocrinol 613(31):917-921

31. Franik S, Kremer JA, Nelen WL, Farquhar C (2014) Aromatase inhibitors for subfertile women with polycystic ovary syndrome. The Cochrane database of systematic reviews 640:CD010287

\section{Publisher's Note}

Springer Nature remains neutral with regard to jurisdictional claims in published maps and institutional affiliations.

\section{Submit your manuscript to a SpringerOpen ${ }^{\circ}$ journal and benefit from:}

- Convenient online submission

- Rigorous peer review

- Open access: articles freely available online

- High visibility within the field

- Retaining the copyright to your article

Submit your next manuscript at $\boldsymbol{\nabla}$ springeropen.com 